\title{
APOE $\varepsilon 4$ Modulation of Training Outcomes in Several Cognitive Domains in a Sample of Cognitively Intact Older Adults
}

\author{
Ramón López-Higes ${ }^{\mathrm{a}, 1}$, Inmaculada C. Rodríguez-Rojo ${ }^{\mathrm{a}, \mathrm{b}, 1}$, José M. Prados $^{\mathrm{a}, *}$, Pedro Montejo , $^{\mathrm{c}}$ \\ David Del-Río $^{\mathrm{a}, \mathrm{b}}$, María Luisa Delgado-Losada ${ }^{\mathrm{a}}$, Mercedes Montenegro ${ }^{\mathrm{c}}$, David López-Sanz $^{\mathrm{a}, \mathrm{b}}$ \\ and Ana Barabash ${ }^{\mathrm{d}, \mathrm{e}}$ \\ ${ }^{a}$ Department of Cognitive Processes, Complutense University of Madrid, Madrid, Spain \\ ${ }^{\mathrm{b}}$ Cognitive and Computational Neuroscience Laboratory, Madrid, Spain \\ ${ }^{\mathrm{c} C e n t e r ~ f o r ~ t h e ~ P r e v e n t i o n ~ o f ~ C o g n i t i v e ~ I m p a i r m e n t, ~ M a d r i d-S a l u d, ~ M a d r i d, ~ S p a i n ~}$ \\ ${ }^{\mathrm{d}}$ Laboratory of Psychoneuroendocrinology and Genetics, San Carlos Clinical Hospital, Madrid, Spain \\ ${ }^{\mathrm{e}}$ Institute of Sanitary Investigation, San Carlos Clinical Hospital, Madrid, Spain
}

Accepted 10 April 2017

Abstract.

Background: Most research points to the $\varepsilon 4$ allele of the apolipoprotein $\mathrm{E}(A P O E)$ gene as the most recognizable genetic risk factor associated with Alzheimer's disease pathogenesis. It has been also suggested that the APOE $\varepsilon 4$ allele has a negative influence on cognitive functioning, which begins long before cognitive impairment becomes manifest. However, still, little is known about the $A P O E \varepsilon 4$ interaction with cognitive intervention programs.

Objective: The main goal of this study was to explore whether there was a differential $A P O E$ genotype modulation effect after cognitive training in different domains, such as language comprehension, executive functions, and memory. Contrary to other studies, hippocampal volume was controlled for.

Methods: Fifty older adults (65+ years; 30 women and 20 men) participated in a multi-domain cognitive training that involved 30 sessions taking place over 12 weeks. Half of the participants were APOE $\varepsilon 4$ carriers. The control group was matched in age, gender, normalized hippocampal volume, cognitive reserve, Mini-Mental State Examination score, and Geriatric Depression Scale-Short Version.

Results: The study revealed that there were consistent treatment benefits in complex sentence comprehension (noncanonical sentences and sentences with two propositions), a domain that was not directly trained, but only in the $A P O E \varepsilon 4$ noncarrier group.

Conclusion: Genetic profile modulates training outcomes in sentence comprehension.

Keywords: Apolipoprotein E, cognitive training, elderly, neuropsychology

\section{INTRODUCTION}

Nowadays, the study of treatments that could prevent cognitive decline is being fostered. In particular, cognitive training interventions have recently been

\footnotetext{
${ }^{1}$ These authors contributed equally to this work.

*Correspondence to: Jose M. Prados, PhD, Department of Cognitive Processes, Complutense University of Madrid, 28223Pozuelo de Alarcón, Madrid, Spain. Tel.: +34 639 957129; E-mail: jomprado@ucm.es.
}

demonstrated to yield positive results [1,2]. However, there is considerable controversy regarding this issue $[3,4]$. There is scientific evidence that neuropsychological therapies in cognitively intact geriatric populations lead to improvements in various cognitive domains. For example, in a longitudinal study that used a training program in memory, reasoning, and processing speed in older adults without memory complaints, the results showed that the benefits were mainly produced in processing speed and reasoning 
and to a lesser extent in memory. Most importantly, the benefits persisted over two years [5, 6]. Similarly, results from follow-up publications on the ACTIVE study that have been performed for up to 10 years, have reported that training in processing speed was associated with a reduced risk of developing dementia 10 years later [7]. Other studies employing a multimodal intervention (which combines the promotion of healthy habits and cognitive training) have managed to improve or maintain cognitive functioning in older people at risk of dementia [8]. Nevertheless, in a recent systematic review and meta-analysis, Lampit and collaborators [9] found that computerized cognitive training's overall effect on cognitive performance in healthy older adults was positive but small. In addition, it was ineffective for executive functions and verbal memory. Their analysis also showed that the efficacy varied by cognitive outcome and was mainly determined by design choices, that is, group-based training was effective, but the home-based modality was not. Interestingly, training more than three times a week was found to be counterproductive.

On another hand, there is growing interest in determining how certain genetic profiles could modulate cognitive functioning. In fact, it is well known that the genetic load could account for individual differences found between brain parameters and cognitive achievement [10]. The $\varepsilon 4$ allele of the apolipoprotein $\mathrm{E}(A P O E)$ gene is the most recognizable genetic risk factor associated with Alzheimer's disease (AD) pathogenesis [11-14]. This polymorphic gene is located on chromosome 19 and has 3 allelic variants $(\varepsilon 2, \varepsilon 3$, and $\varepsilon 4)$, which encode for three protein isoforms that differ only in the substitution of one or two amino acids (cysteine or arginine) at positions 112 and 158 [15-17]. Apolipoprotein E (ApoE) isoforms have a variety of functions such as regulating brain lipid transport, neuronal signaling, glucose metabolism, neuroinflammation, and mitochondrial function [18] and they also differentially modulate the metabolism and aggregation of the amyloid- $\beta$ peptide in the brain $[19,20]$. The carriage of the $A P O E$ $\varepsilon 4$ allele has been related to an increased glial activation, oxidative stress, or neuronal injury [21], which could result in altered brain repair mechanisms and a less effective neural protection [22]. Furthermore, ApoE $\varepsilon 3$ is the normal and most common isoform among the population, and ApoE $\varepsilon 2$ has been linked to protection against $\mathrm{AD}$ and has been also suggested to have a positive influence on cognitive health [23].

As mentioned, the negative effect of the $A P O E \varepsilon 4$ allele is not only confined to those suffering AD. It is also found in people with mild cognitive impairment, subjective cognitive decline, or in cognitively intact older adults. This indicates that its influence on cognitive functioning begins long before cognitive impairment becomes manifest [24-26], even when people present a high cognitive performance profile [27]. The $\varepsilon 4$ allele has been mainly associated with impairments in episodic memory [28-31] and executive functions (EF) $[32,33]$. A meta-analysis that evaluated the effect of the APOE genotype on cognition also confirmed the negative effects of the $\varepsilon 4$ allele on processing speed, executive functioning, and episodic memory in old age [34]. However, in a previous meta-analysis, Small and colleagues [35] suggested that this effect was very small in that age group. In addition, studies that have taken into account both age at onset of $\mathrm{AD}$ and $A P O E$ $\varepsilon 4$ carriage have found that, compared to late onset $\varepsilon 4$ carriers, early onset noncarriers showed faster decline in language, attention, executive, and visuospatial functioning. In other words, patients with AD exhibit cognitive decline in non-memory cognitive domains despite not having either risk factor (i.e., old age and $\varepsilon 4$ allele carriage) [36]. In this sense, and closely related to the latter, it has been reported that the $A P O E \& 4$ allele could have an antagonistic pleiotropy, such that young $\varepsilon 4$ carriers (age range 18-30 years) have shown favorable effects of this carriage status on cognitive performance $[37,38]$ in contrast with the development of detrimental consequences as people age [39, 40]. An example of better cognitive performance in young adults with the $A P O E \& 4$ genotype is the study carried out by Stening and collaborators [41]. They found, in contrast to the results obtained by the noncarrier group, that the carriage of the $A P O E \varepsilon 4$ allele had a positive impact on spatial tasks and on an episodic memory task with spatial components. However, other studies with young $\varepsilon 4$ carriers have shown no $A P O E$ genotype-dependent differences in cognitive performance $[42,43]$. This all translates into a panorama of great complexity, where multiple variables (e.g., not only biological but also environmental or social factors) could be affecting the final outcome in cognitive functioning.

To our knowledge and directly related to the aim of the study, there are only a few papers examining how a risk genotype could moderate cognitive training effects, which ultimately might contribute to a beneficial or negative association with the particular condition of an individual. For example, Feng et al. [32] assessed the interaction between the 
long-term effects of a multi-domain cognitive training and $A P O E$ genotype on cognitive function in community-dwelling older adults of Shangai. The sample population received 24 training sessions over 12 weeks. The authors found that cognitive training reduced the decline in processing speed over time regardless of the $A P O E$ genotype. However, the carriers of the $A P O E \varepsilon 4$ allele presented reductions in $\mathrm{EF}$ over time, although training attenuated the $\varepsilon 4$ negative effect on processing speed. In addition, they observed that $A P O E \& 2$ allele carriers also benefited from training, particularly in measures of $\mathrm{EF}$ and verbal memory. On another hand, Polito and coworkers [44] employed 10 twice-weekly meetings to evaluate short-term efficacy of cognitive stimulation (CS) focused on a specific cognitive area that changed from session to session (executive reasoning, language-verbal fluency, semantic memory, etc.). They evaluated the influence of the APOE $\varepsilon 4$ carrier status in cognitively healthy individuals with a family history of dementia (NDFAM) and in non-demented individuals with cognitive impairment. As a result, they showed that CS was an effective treatment in cognitively healthy NDFAM (as shown in higher net gain in the Montreal Cognitive Assessment), whereas it was less effective in individuals with cognitive impairment. Moreover, they observed that the noncarriers in the cognitively healthy NDFAM group benefited from CS, as evidenced by improved cognitive performance (particularly, in visuospatial memory function), whereas the APOE $\varepsilon 4$ carriers showed no significant improvement. Finally, a study carried out by Zehnder et al. [45] measured the practice effect on cognitive performance by applying two neuropsychological assessment instruments in physically and mentally cognitively intact aged people (with a mean age of 70 years): initially at baseline and then, two years later. Their results indicated that the $\varepsilon 4$ allele of the $A P O E$ gene had a negative impact on cognitive performance, notably on episodic memory tasks (such as immediate verbal learning and delayed recall). Furthermore, practice effects seen in carriers of the $A P O E \& 4$ allele were inferior in most tested areas to the effects found among the noncarriers.

The present study has an underlying hypothesis based on previous developments and considerations. In other words, the effect of cognitive training would differ depending on the APOE genotype, with allele $\varepsilon 4$ carriers showing worse outcomes (or no effect) in different cognitive domains (memory, EF, and language comprehension) than the noncarrier group.

\section{MATERIALS AND METHODS}

\section{Participants}

We selected 25 APOE $\varepsilon 4$ carriers from a larger sample of healthy older adults who voluntarily participated in a study about normal and pathological aging. All of them had a score higher than 24 points in the Mini-Mental State Examination (MMSE) [46, 47] and a score below 5 in the Yesavage Geriatric Depression Scale-Short Version (GDS-15) [48]. Then, we also selected $A P O E \& 4$ noncarriers matched in gender (15 women and 10 men in both groups), age, MMSE score, GDS-15, and overall cognitive reserve (estimated by a questionnaire; see materials below). All participants were assessed in the Center for Prevention of Cognitive Impairment of Madrid-Salud, nursing homes or day centers in the city of Madrid (Spain). There were no significant group differences (APOE $\varepsilon 4$ carriers versus noncarriers) in any of the variables mentioned. Although it was not considered a criterion for participants' selection, we confirmed that there were no group differences in normalized hippocampal volume (see Table 1 for descriptive statistics related to all these variables). As $A P O E$ $\varepsilon 4$ is considered a risk factor for cardiac disease, we explored a possible group difference in the number of cardiovascular diseases. Although there were more participants with cardiovascular diseases in the group of $A P O E \varepsilon 4$ carriers $(n=7)$ than in the noncarriers $(n=2)$, the difference did not reach statistical significance, $\chi^{2}(1)=3.38, p=0.06$.

The study complied with the ethical standards of the Declaration of Helsinki and was approved by the local ethics committees of the participant institutions.

Table 1

Descriptive statistics (mean and standard deviation) of variables in which groups were matched

\begin{tabular}{llccc}
\hline & & $n$ & Mean & $S D$ \\
\hline Age & APOE $\varepsilon$ 4 carriers & 25 & 71.64 & 5.715 \\
& Noncarriers & 25 & 71.68 & 5.647 \\
MMSE & APOE $\varepsilon 4$ carriers & 25 & 27.72 & 1.720 \\
& Noncarriers & 25 & 28.44 & 1.635 \\
GDS-15 & APOE $\varepsilon 4$ carriers & 25 & 1.68 & 2.231 \\
& Noncarriers & 25 & 1.88 & 1.424 \\
CRQ & APOE $\varepsilon 4$ carriers & 25 & 13.76 & 4.447 \\
& Noncarriers & 25 & 14.04 & 4.430 \\
NHV & APOE $\varepsilon 4$ carriers & 22 & 0.0047083 & 0.00070081 \\
& Noncarriers & 20 & 0.0050303 & 0.00040590 \\
\hline
\end{tabular}

MMSE, Mini-Mental State Examination; GDS-15, Geriatric Depression Scale - Short Version; CRQ, Cognitive Reserve Questionnaire; NHV, normalized hippocampal volume. 


\section{Normalized hippocampal volume}

A General Electric 1.5 Tesla magnetic resonance scanner was employed to acquire a T1-weighted image for each participant. A high-resolution antenna and a homogenization PURE filter (Fast Spoiled Gradient Echo sequence, TR/TE/TI $=11.2 / 4.2 / 450 \mathrm{~ms}$; flip angle $12^{\circ} ; 1 \mathrm{~mm}$ slice thickness, $256 \times 256$ matrix and FOV $25 \mathrm{~cm}$ ) were used. MRI images were processed with Freesurfer software (version 5.1.0) and its specialized tool for automated cortical and subcortical segmentation [49]. Hippocampal volumes were selected to match both groups. Hippocampal volume values were normalized with respect to the overall intracranial volume to account for differences in head volume across participants.

\section{APOE genotyping}

Genomic DNA was extracted from $10 \mathrm{ml}$ blood samples in ethylenediaminetetraacetic acid (EDTA) of cognitively intact older participants. APOE haplotype was determined by analyzing single nucleotide polymorphisms (SNPs) rs7412 and rs429358 genotypes with TaqMan assays, using an Applied Biosystems 7900 HT Fast Real Time PCR machine (Applied Biosystems, Foster City, CA). A genotyping call rate over $90 \%$ per plate, sample controls for each genotype, and negative sample controls were included in each assay. Three well-differentiated genotyping clusters for each SNP were required to validate results. Intra- and interplate duplicates of several DNA samples were included.

\section{Cognitive training program: UMAM}

An extensive description of the cognitive training program (Programa de la Unidad de Memoria del Ayuntamiento de Madrid: UMAM [50]) [English trans. Madrid City Council Memory Unit Program], can be found in the Supplementary Material. Briefly, the UMAM training program consisted of 30 sessions: 28 of them carried out within three months and two more considered as maintenance sessions. Each session lasted $90 \mathrm{~min}$ and was structured with its objectives, materials, and specific activities. The training was organized in groups of 14-16 people. The program was divided into four training areas: (1) cognitive stimulation; (2) memory concepts; (3) management of forgetting everyday experiences; and (4) meta-memory training.
Design

An extensive neuropsychological assessment (see Materials subsection below) of each participant was conducted at two moments: one at the beginning, immediately after recruitment (baseline: $t_{0}$ ), and six months later (endpoint: $t_{1}$ ). Once a participant decided to voluntarily participate in the study she/he was randomly assigned to one of the two conditions of cognitive training: immediate (between baseline and endpoint assessment, i.e., $t_{0}$ and $t_{1}$ ) or delayed (training after the endpoint assessment, i.e., after $t_{1}$ ). Thus, this study has a mixed factorial design, with genetic profile and cognitive training as between-subject variables, and the assessment time (baseline, endpoint) as the intra-subject variable.

\section{Materials}

In order to establish the participants' cognitive status, they all underwent a neuropsychological assessment of three cognitive domains: memory, $\mathrm{EF}$, and sentence reading comprehension. Memory was assessed with the Logical Memory and Word List from the Wechsler Memory Scale-III (WMS-III Spanish version; Wechsler, 2004) [51], and EF were assessed by the Stroop test [52].

The ECCO_Senior test (Exploración Cognitiva de la Comprensión de Oraciones) [English translation: Cognitive Assessment of Sentence Comprehension], developed by López-Higes, Rubio, Martín-Aragoneses, Del Río, and Mejuto [53], was used to assess grammatical reading comprehension. This test evaluates the thematic role assignment process (who did what to whom) through a simple verification task involving 36 sentence-picture pairs (visually presented) that are either congruent or incongruent. Incongruent items are syntactic or lexical foils. In syntactic foils (see Illustration 1), thematic roles are reversed in the picture with respect to the sentence statements, unlike in lexical foils (see Illustration 2), where there is a change in the picture with regard to an action, a person, or an object included in the sentence. Each type of sentence has specific features in two dimensions: propositional density ( 1 or 2 propositions) and syntactic complexity (defined by their matching the canonical word order in Spanish: canonical versus non-canonical sentences). Most Spanish sentences follow the canonical Subject-Verb-Object word order, so that the word located in the initial position has the greatest prominence as an argument and receives the 


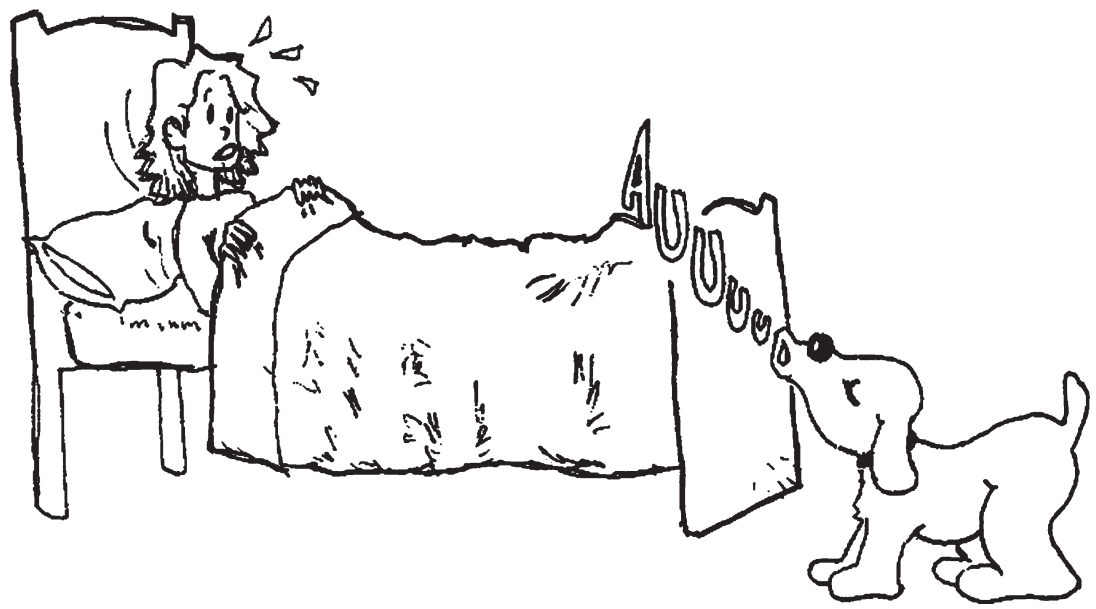

Illustration 1. Example of a syntactic foil in the sentence comprehension test. It was the dog that awakened the woman. True or False?
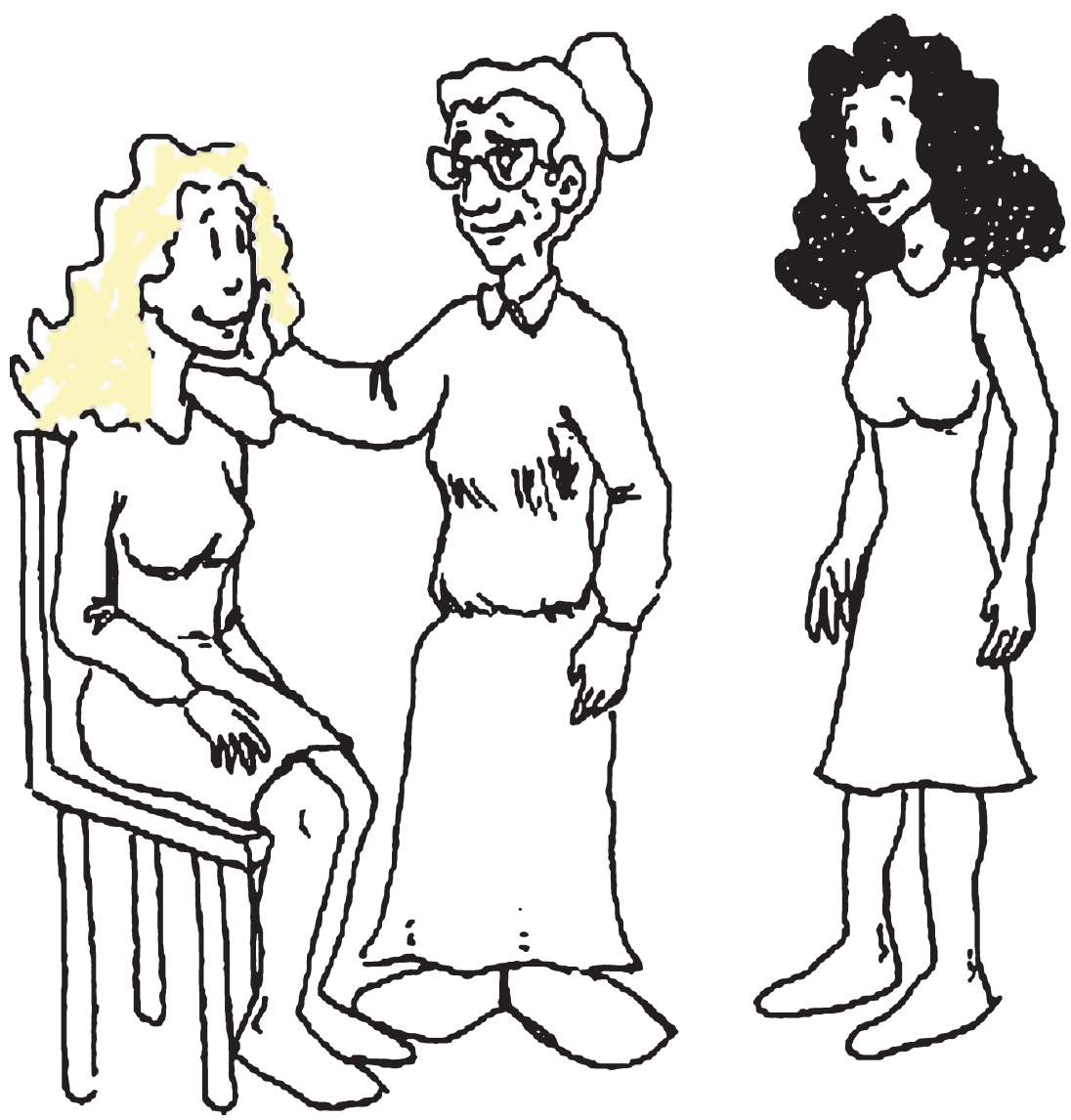

Illustration 2. Example of a lexical foil in the sentence comprehension test. The woman kissed by the grandmother was sitting on a chair. True or False?

thematic role of the agent. However, in Spanish, as in other languages, the linear position of the constituents can vary depending on discursive and contextual factors, as in passive sentences, where the correspondence between the linear order of words and the assignment of thematic roles is different from that of the canonical Subject-Verb-Object order. 
Finally, to estimate cognitive reserve, participants completed the Cognitive Reserve Questionnaire (CRQ) [54]. The CRQ consists of 8 items that measure various aspects of the participants' intellectual activity: education, attainment of training courses, parents' education, lifetime occupation, musical training, and knowledge of languages. The CRQ also asks participants how often they carry out activities such as reading and practicing intellectual games (puzzles and chess).

\section{Procedure}

Participants' neuropsychological assessment was conducted at two moments, one at the beginning, immediately after recruitment (baseline: $t_{0}$ ), and then six months after that (endpoint: $t_{1}$ ) by an experienced psychologist or psychiatrist in the Center for the Prevention of Cognitive Impairment of Madrid-Salud. Regarding the baseline phase, in the first session, participants completed the screening tests (MMSE, GDS-15), as well as the CRQ. In this session, participants were informed about the main goals of the study and signed an informed consent document. All the remaining neuropsychological and cognitive tests were carried out in two additional sessions, each lasting approximately $50 \mathrm{~min}$. Although there was a block of tests for each session, the order of presentation of the tests was randomized in each session. Neuropsychological tests were administered and scored following the standard instructions provided in the users' manuals. At the endpoint, the same set of neuropsychological tests administered at baseline was used again to assess participants' performance in the same cognitive domains (memory, executive functions, and sentence comprehension).

\section{Participant flow diagram}

In order to clarify all the details regarding total sample recruitment, baseline assessment, random assignment to a training group, the UMAM program intervention, the endpoint measure, and the inclusion criteria finally used to select the 50 participants enrolled in the present study, we present the following flow chart (Fig. 1).

\section{Statistical analysis}

In the ECCO-Senior test sentence comprehension task, we obtained only two dependent measures (the number of correct responses) before analysis: (1) noncanonical sentences (NoCS) and (2) sentences with two propositions or verbs (S2P). We computed the interference index proposed by Chafetz and Matthews [55] for the Stroop test.

The following primary dependent measures were selected for the study: Word List (WL) and Logical Memory (LM) performance in the delayed recall condition (WMS-III Spanish version), the Stroop interference index, participants' performance in NoCS and S2P from the ECCO-Senior test, and the GDS-15 score.

A mixed linear model (MLM) approach was used to test main effects of Genetic Profile (APOE $\varepsilon 4$ carriers versus noncarriers), Cognitive Training (immediate versus delayed), and their interactions. An additional (repeated measures) factor coding Assessment Time (baseline versus endpoint) was introduced to account for effects attributable to cognitive training. MLMs have been previously recommended, as they can better account for individual variability in repeated measurements over time and, relative to other analytical methods, they also handle missing data more appropriately [56]. Our main goal was to explore a possible differential $A P O E$ genotype modulation effect of cognitive training benefits on memory, EF, and sentence comprehension. Thus, separate MLMs were estimated for each dependent variable, using IBM SPSS 20.0. In case of a significant interaction among the three previously mentioned factors (Genetic Profile $\times$ Cognitive Training $\times$ Assessment Time), the only relevant pairwise comparison would be that involving APOE $\varepsilon 4$ carriers and noncarriers with immediate training, since it is the main goal of the study. However, in addition we computed all post-hoc comparisons with the SPSS Generalized Linear Model procedure, simply using the difference between $\mathrm{t} 1$ (endpoint) and t0 (baseline) in the corresponding dependent variable for a specific condition (Genetic Profile $\times$ Cognitive Training) under consideration. We used the Bonferroni test, based on Student's $t$-statistic, which corrects the level of significance observed by the fact that multiple comparisons are made. Effect sizes were estimated by means of partial eta-square $\left(\eta_{\mathrm{p}}^{2}\right)$.

\section{RESULTS}

Table 2 shows descriptive statistics for each dependent measure by condition (Genetic Profile $\times$ Cognitive Training) at baseline $\left(t_{0}\right)$ and endpoint $\left(t_{1}\right)$. 


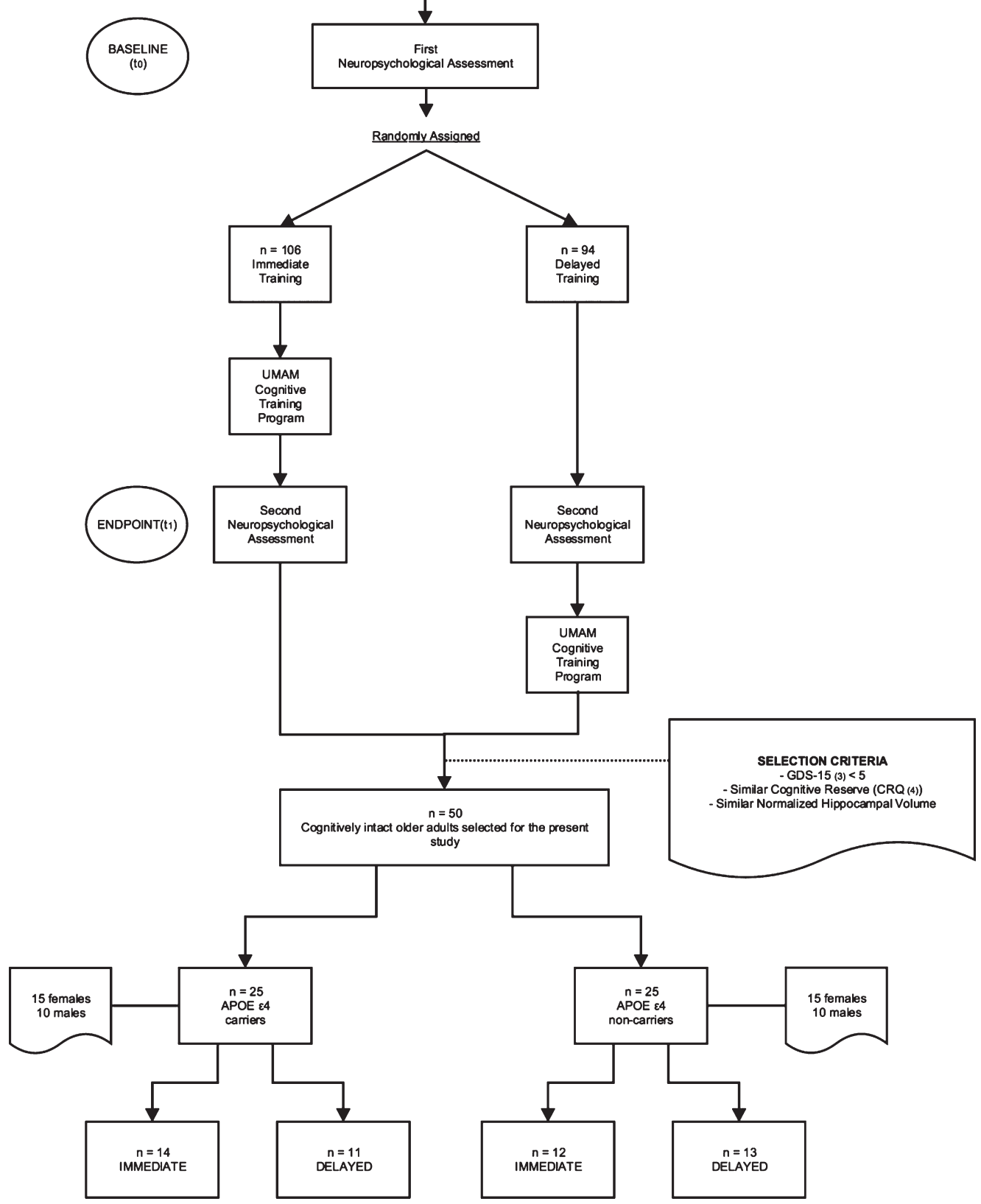

Fig. 1. Flow chart showing all phases in the global study. The flow chart shows the general inclusion criteria for the 200 participants enrolled in the research project and how the selection of the 50 participants was carried out for the present study considering their $A P O E \varepsilon 4$ genotype. All of them were given two neuropsychological assessments: the first one at the baseline ( 0 months) and the second one at the endpoint (6 months). The UMAM cognitive training program was also applied to two different groups and in two different times: between the baseline and the endpoint period where both neuropsychological assessments took place (immediate group) and beyond the endpoint (delayed group). (1) Wechsler Memory Scale-III; (2) Mini-Mental State Examination; (3) Geriatric Depression Scale-Short Version; (4) Cognitive Reserve Questionnaire. 


\section{APOE $\varepsilon 4$ modulation of training outcomes in memory and EF selected measures}

Regarding results obtained for dependent memory measures, the analysis revealed that the only factor that had an effect on participants' performance in WL and LM was Assessment Time (see Table 3). Memory measures were higher in $t_{1}$ than in $t_{0}$ (with the exception of one condition in which they were almost equal).

With respect to the Stroop interference index (see Table 3) the results pointed out that $A P O E \varepsilon 4$ noncarriers had greater inhibition control than the carriers, but no other effect reached statistical significance.

\section{APOE $\varepsilon 4$ modulation of training outcomes in language comprehension}

In ECCO's noncanonical sentences, the analysis revealed that there was a significant main effect of Assessment Time, as well as a significant interaction between Genetic Profile $\times$ Cognitive Training $\times$ Assessment Time (see Table 4). Post-hoc comparison between $A P O E \varepsilon 4$ carriers and noncarriers who had received immediate cognitive training did not reach statistical significance. Neither of remaining pairwise comparisons were significant. In sentences with two propositions, there was also a significant main effect of Assessment Time and a significant interaction among the three factors (see Table 4). Post hoc comparisons between conditions of interest (i.e., $A P O E \varepsilon 4$ carriers and noncarriers who had received immediate cognitive training), showed that there was a benefit in $A P O E \varepsilon 4$ noncarriers in sentence comprehension scores after training, whereas in the carriers, $t_{1}-t_{0}$ differences were close to zero ( $\mathrm{I}-\mathrm{J}=-2.47$; standardized error $=0.895$, Bonferroni $p=0.035$, Wald 95\% CI [-4.22, -0.71], $\eta_{\mathrm{p}}^{2}=0.212$ ). Results in post-hoc comparisons also revealed for these items (S2P) that there was an effect of cognitive training (immediate versus delayed) in $A P O E$ $\varepsilon 4$ noncarriers' group: I $-\mathrm{J}=2.70$, standardized error $=0.930$; Bonferroni $p=0.022$, Wald $95 \%$ CI $[0.87,4.52]$.

\section{Could APOE $\& 4$ be related to training outcomes in mood?}

Considering that some authors have reported apparent collateral benefits of cognitive training programs in mood, we also explored the possible modulation effect of $A P O E \varepsilon 4$ carriage on training outcomes in this domain. When GDS-15 scores were considered, there was a main effect of assessment time, an interaction between Genetic Profile and Assessment Time, and finally, a significant interaction among the three variables included in the analysis (see Table 5). As in the previous subsection, we computed a planned post-hoc comparison between $A P O E \& 4$ carriers and noncarriers who had received immediate cognitive training. Results revealed a positive effect of cognitive training on GDS-15 scores in the group of $A P O E \varepsilon 4$ noncarriers (negative difference) and differences close to zero

Table 2

Neuropsychological scores of $A P O E \varepsilon 4$ allele carriers and noncarriers

\begin{tabular}{|c|c|c|c|c|}
\hline & \multicolumn{2}{|c|}{ APOE \&4 carriers } & \multicolumn{2}{|c|}{ APOE $\varepsilon 4$ noncarriers } \\
\hline & \multicolumn{4}{|c|}{ BASELINE } \\
\hline & $\begin{array}{c}\text { Immediate } \\
\text { training } \\
M(S D)\end{array}$ & $\begin{array}{c}\text { Delayed } \\
\text { training } \\
M(S D)\end{array}$ & $\begin{array}{c}\text { Immediate } \\
\text { training } \\
M(S D)\end{array}$ & $\begin{array}{l}\text { Delayed } \\
\text { training } \\
M(S D)\end{array}$ \\
\hline WMS-III: Words delayed recall & $5.93(3.91)$ & $4.09(2.62)$ & $5.67(2.27)$ & $6.08(3.70)$ \\
\hline WMS-III: LM Topics delayed recall & $10.00(3.57)$ & $9.64(3.98)$ & $10.50(2.15)$ & $10.85(2.51)$ \\
\hline Stroop Interference index & $2.91(5.33)$ & $0.14(5.08)$ & $7.58(8.22)$ & $7.73(10.84)$ \\
\hline ECCO-Senior: NoCS & $14.42(2.34)$ & $14.20(1.75)$ & $13.75(2.56)$ & $14.08(1.92)$ \\
\hline ECCO-Senior: S2P & $15.21(2.54)$ & $14.90(1.59)$ & $13.91(2.77)$ & $14.41(2.71)$ \\
\hline \multirow[t]{2}{*}{ GDS-15 } & $1.50(2.34)$ & $1.91(2.16)$ & $1.92(1.38)$ & $1.85(1.52)$ \\
\hline & \multicolumn{4}{|c|}{ ENDPOINT } \\
\hline WMS-III: Words delayed recall & $7.85(3.50)$ & $5.63(3.15)$ & $7.08(2.71)$ & $8.50(3.50)$ \\
\hline WMS-III: LM Topics delayed recall & $11.23(2.58)$ & $9.25(2.60)$ & $11.33(2.06)$ & $12.67(0.86)$ \\
\hline Stroop Interference index & $8.12(4.09)$ & $-0.10(6.12)$ & $5.89(8.46)$ & $8.49(11.67)$ \\
\hline ECCO-Senior: NoCS & $14.69(2.35)$ & $15.14(1.77)$ & $15.50(1.77)$ & $14.18(2.60)$ \\
\hline ECCO-Senior: S2P & $15.53(2.66)$ & $15.28(2.05)$ & $16.20(1.54)$ & $14.45(2.69)$ \\
\hline GDS-15 & $1.64(2.13)$ & $1.44(1.59)$ & $0.67(0.88)$ & $1.20(1.62)$ \\
\hline
\end{tabular}

APOE $\varepsilon$ 4, Apolipoprotein E epsilon 4; LM, logical memory; ECCO, Cognitive Assessment of Sentence Comprehension; NoCS, noncanonical sentences; S2P, sentences with two propositions; GDS-15, Geriatric Depression Scale-Short Version. 
Table 3

Mixed linear model results in memory and EF domains

\begin{tabular}{|c|c|c|c|c|c|}
\hline Dependent variable & Effect & $F$ & $d f$ & $p$ & $\eta_{\mathrm{p}}^{2}$ \\
\hline \multirow{7}{*}{$\begin{array}{l}\text { List of Words delayed recall } \\
\text { (WMS-III) }\end{array}$} & Genetic profile & 0.783 & $1,49.193$ & 0.381 & \multirow{7}{*}{0.358} \\
\hline & Cognitive training & 0.709 & $1,49.193$ & 0.404 & \\
\hline & Assessment time & 26.041 & $1,43.524$ & 0.000 & \\
\hline & Genetic profile $\times$ Cognitive training & 1.892 & $1,49.193$ & 0.175 & \\
\hline & Genetic profile $\times$ Assessment time & 0.114 & $1,43.524$ & 0.738 & \\
\hline & Cognitive training $\times$ Assessment time & 0.001 & $1,43.524$ & 0.979 & \\
\hline & Genetic profile $\times$ Cognitive training $\times$ Assessment time & 0.033 & $1,43.524$ & 0.858 & \\
\hline \multirow{7}{*}{$\begin{array}{l}\text { Logical Memory of Topics } \\
\text { delayed recall (WMS-III) }\end{array}$} & Genetic profile & 3.176 & $1,47.626$ & 0.081 & \multirow{7}{*}{0.076} \\
\hline & Cognitive training & 0.044 & $1,47.626$ & 0.835 & \\
\hline & Assessment time & 4.522 & $1,44.385$ & $\mathbf{0 . 0 3 9}$ & \\
\hline & Genetic profile $\times$ Cognitive training & 1.405 & $1,47.626$ & 0.242 & \\
\hline & Genetic profile $\times$ Assessment time & 0.657 & $1,44.385$ & 0.422 & \\
\hline & Cognitive training $\times$ Assessment time & 0.112 & $1,44.385$ & 0.740 & \\
\hline & Genetic profile $\times$ Cognitive training $\times$ Assessment time & 1.203 & $1,44.385$ & 0.279 & \\
\hline \multirow[t]{7}{*}{ Stroop Interference index } & Genetic profile & 4.561 & $1,50.392$ & $\mathbf{0 . 0 3 8}$ & \multirow[t]{7}{*}{0.109} \\
\hline & Cognitive training & 0.906 & $1,50.392$ & 0.346 & \\
\hline & Assessment time & 1.390 & $1,44.019$ & 0.245 & \\
\hline & Genetic profile $\times$ Cognitive training & 2.293 & $1,50.392$ & 0.136 & \\
\hline & Genetic profile $\times$ Assessment time & 3.354 & $1,44.019$ & 0.074 & \\
\hline & Cognitive training $\times$ Assessment time & 0.376 & $1,44.019$ & 0.543 & \\
\hline & Genetic profile $\times$ Cognitive training $\times$ Assessment time & 2.574 & $1,44.019$ & 0.116 & \\
\hline
\end{tabular}

Table 4

Mixed linear model results in sentence comprehension

\begin{tabular}{|c|c|c|c|c|c|}
\hline Dependent variable & Effect & $F$ & $d f$ & $p$ & $\eta_{\mathrm{p}}^{2}$ \\
\hline \multirow[t]{7}{*}{ NoCS } & Genetic profile & 0.239 & $1,49.204$ & 0.627 & \\
\hline & Cognitive training & 0.086 & $1,49.204$ & 0.770 & \\
\hline & Assessment time & 6.528 & $1,44.724$ & 0.014 & 0.148 \\
\hline & Genetic profile $\times$ Cognitive training & 0.602 & $1,49.204$ & 0.442 & \\
\hline & Genetic profile $\times$ Assessment time & 0.165 & $1,44.724$ & 0.686 & \\
\hline & Cognitive training $\times$ Assessment time & 0.425 & $1,44.724$ & 0.518 & \\
\hline & Genetic profile $\times$ Cognitive training $\times$ Assessment time & 4.665 & $1,44.724$ & 0.036 & 0.127 \\
\hline \multirow[t]{7}{*}{$\mathrm{S} 2 \mathrm{P}$} & Genetic profile & 0.597 & $1,49.415$ & 0.443 & \\
\hline & Cognitive training & 0.570 & $1,49.415$ & 0.454 & \\
\hline & Assessment time & 6.517 & $1,45.247$ & 0.014 & 0.148 \\
\hline & Genetic profile $\times$ Cognitive training & 0.225 & $1,49.415$ & 0.637 & \\
\hline & Genetic profile $\times$ Assessment time & 1.644 & $1,45.247$ & 0.206 & \\
\hline & Cognitive training $\times$ Assessment time & 2.795 & $1,45.247$ & 0.101 & \\
\hline & Genetic profile $\times$ Cognitive training $\times$ Assessment time & 4.453 & $1,45.247$ & 0.040 & 0.117 \\
\hline
\end{tabular}

NoCS, noncanonical sentences in the ECCO-Senior; S2P, sentences with two prepositions in the ECCO-Senior.

in the $A P O E \& 4$ carriers: $\mathrm{I}-\mathrm{J}=1.39$; standardized error $=0.418$; Bonferroni, $p=0.005$, Wald $95 \%$ CI $[0.57,2.21], \eta_{\mathrm{p}}^{2}=326$. No other post-hoc comparison reached statistical significance.

\section{DISCUSSION}

In this study, we examined in a sample of cognitively intact older adults whether cognitive training benefits may be modulated by the carriage of the $A P O E \varepsilon 4$ allele, the most important genetic risk factor for late-onset $\mathrm{AD}$. For this purpose, several cognitive domains such as memory performance, $\mathrm{EF}$, and language comprehension were differentially explored.
Regarding the effects of genetic profile on cognitive training outcomes in the domain of memory, the results obtained revealed that this factor did not modulate training benefits in any of the memory measures considered in the study. Thus, the UMAM program was not efficacious in the delayed recall measures in either of the two groups assessed (APOE $\varepsilon 4$ carriers and noncarriers). This contradicts a number of studies that have shown the benefits of cognitive training in memory. In fact, the possibility of memory empowerment and compensation observed in several studies [57] has served as a justification for the training programs and cognitive interventions developed in recent years [58]. For example, Novoa et al. [59] 
Table 5

Mixed linear model results in the Geriatric Depression Scale-Short Version (GDS-15)

\begin{tabular}{llrrrr}
\hline Dependent variable & Effect & $F$ & $d f$ & $p$ & $\eta_{\mathrm{p}}^{2}$ \\
\hline GDS-15 & Genetic profile & 0.110 & 50.469 & 0.741 & \\
& Cognitive training & 0.035 & 50.469 & 0.853 & $\mathbf{0 . 0 0 0}$ \\
& Assessment time & 16.441 & 48.217 & $\mathbf{0 . 2 8 1}$ \\
& Genetic profile $\times$ Cognitive training & 0.077 & 50.469 & 0.783 & $\mathbf{0 . 0 7 2}$ \\
& Genetic profile $\times$ Assessment time & 4.392 & 48.217 & $\mathbf{0 . 0 4 1}$ & $\mathbf{0 . 0 7}$ \\
& Cognitive training $\times$ Assessment time & 0.284 & 48.217 & 0.597 & $\mathbf{0 . 1 1 8}$ \\
& Genetic profile $\times$ Cognitive training $\times$ Assessment time & 5.452 & 48.217 & $\mathbf{0 . 0 2 4}$ & $\mathbf{0 . 2 1 7}$ \\
\hline
\end{tabular}

found a positive effect on immediate and delayed memory in 8 of the 9 studies they reviewed. Actually, most of these studies applied a similar length of their groups' training sessions as the ones that we administered in the UMAM cognitive training program (i.e., one and a half hour each). Additionally, Martin and colleagues [3] conducted a systematic review of the cognitive training intervention effects on various cognitive functioning domains (i.e., memory, EF, attention, and processing speed), finding that, versus a non-treatment control condition, cognitively intact older adults receiving cognitive training significantly improved their immediate and delayed verbal recall scores.

Our results also contradict those obtained by Zehnder et al. [45], which indicated that practice effects in $A P O E \& 4$ allele carriers were inferior in most tested areas compared to the effects found in the noncarriers, especially in episodic memory functions (immediate verbal learning and delayed recall).

With respect to the Stroop interference index, the results simply showed a main global effect of genetic profile. This means that $A P O E \& 4$ noncarriers had greater inhibition efficacy than $A P O E \varepsilon 4$ carriers, but this factor did not modulate the cognitive training effects. Accordingly, our pattern of results in memory and EF measures altogether contrast with other previous studies showing cognitive training benefits in these domains. For example, in their systematic review and meta-analysis, Kelly et al. [60] explored the impact of cognitive training and mental stimulation on the cognitive and everyday functioning of cognitively intact older adults. Their meta-analysis outcomes revealed that, compared to active controls, training improved cognitively intact older adults' performance on measures of EF (i.e., working memory, processing speed, and composite measures of cognitive function) and memory (i.e., face-name recall, immediate recall, paired associates), but only when comparison was made to the non-intervention condition; and finally, cognitive training also contributed to improve their subjective cognitive function.
However, our findings regarding this issue (i.e., the memory and EF domains) are more in line with the results presented by Lampit and co-workers in their meta-analysis [9], which have already been briefly described in the introduction. The lack of finding analogous results according to much of the literature on this topic could be due to the fact that, in our study, all participants (APOE $\varepsilon 4$ carriers and noncarriers) were independent older adults with no signs of cognitive deterioration or depression and they were matched in different key variables, such as, for example, hippocampal volume. Bearing these considerations in mind, it was more difficult to find group differences than in other studies where the groups were less evenly matched.

On another hand, in relation to the sentence comprehension test (ECCO-Senior) outcomes, we observed significant differences between the endpoint and the baseline measures in sentences with two propositions, but only in the group of noncarriers who received immediate training (reaching a low-moderate effect size). On the contrary, APOE $\varepsilon 4$ carriers with immediate cognitive training did not exhibit any positive effect of treatment on this domain. This means that cognitive training did not produce any benefit for $A P O E \varepsilon 4$ carriers in sentence comprehension. The triple interaction Genetic Profile $\times$ Cognitive Training $\times$ Assessment Time explained $12 \%$ of the total variance of participants' performance in complex sentences. As we mentioned in the results, we have observed a positive effect of cognitive training on S2P's comprehension scores but restricted to noncarriers, that is, a significant improvement from $t_{0}$ (baseline) to $t_{1}$ (endpoint) in those older adults having immediate training in comparison with peers with delayed training.

To our knowledge, the present study is the first one to report the influence of $A P O E \& 4$ carriage status on the efficacy of cognitive training in healthy older individuals' sentence comprehension, measured as a gain in simple picture-sentence verification performance. Interestingly, the UMAM program was not 
explicitly designed to improve language comprehension in older citizens but our results indicate that it produces benefits in this domain, which was not assumed to be directly trained. This result contrasts with some evidence reported in reviews like the one conducted by Novoa et al. [59], in which no pattern of results was found suggesting transference from one domain to another. Specifically, working memory and attentional/interference control tasks have been utilized in training studies, as they constrain higher order cognitive functioning [61]. These tasks can predict success in other tasks, ranging from reading comprehension [62] to reasoning and problem-solving [63-65]. In this sense, the study conducted by Jaeggi et al. [66] revealed that working memory training (which engages executive processes such as inhibition control, monitoring, updating, and dual-task management) led to transfer, improving measures of fluid intelligence. However, several other studies have failed to find transfer [67,68], which suggests controversy about this issue. Regarding the language comprehension results, the UMAM program includes activities related to vocabulary, reading texts, and following instructions, which are all closely related to written language comprehension. This intrinsic feature can lead to positive training outcomes associated with sentence comprehension skills. For example, the UMAM program includes the PQRST method (Preview + Question + Read + Self-recitation + Test) $[69,70]$ to work with texts. So, it might be hypothesized that this procedure, which implies an active reading strategy, could have had a positive effect on sentence comprehension.

It should also be noted that we observed an unintended effect on cognitive training outcomes in older peoples' scores on the GDS-15 related to the genetic profile modulation. Our results showed that a significant reduction at the endpoint in this test was only confirmed in the group of $A P O E \varepsilon 4$ noncarriers who received cognitive training immediately (the post-hoc contrast reached a moderate effect size). In this case, the triple interaction Genetic Profile $\times$ Cognitive Training $\times$ Assessment Time explained about $12 \%$ of the total variance of participants' scores on the GDS-15. APOE $\varepsilon 4$ carriers did not show any benefit from training in this domain. These findings are completely consistent with those recently obtained by Hill et al. [71]. However, considering that this scale is mainly used for screening, we must be cautious when interpreting this collateral training effect on mood, as all subjects had normal scores on the GDS-15 (that is, between 0 and 5). Therefore, future research should assess mood and psychological well-being using the most appropriate scales for this purpose, and always considering the modulating effect of social support.

In conclusion, the present study revealed that the genetic profile modulates cognitive training outcomes in complex sentence comprehension, and possibly, in mood, two domains that were not directly trained or included as specific goals of the administered cognitive intervention program.

\section{Limitations and future directions}

The evidence presented here highlights the importance of public policies directed at keeping cognitively intact older adults mentally active through specific training programs.

However, our sample was somewhat small, although the groups were quite restrictively matched in different variables, such as hippocampal volume. As it has been shown that carriers of the APOE $\varepsilon 4$ allele are more susceptible to presenting reductions in this cerebral region [72-75], the genetic profile differences found in our study could be more exclusively confined to the cognitive training effects. This would support the notion that some populations with certain positive characteristics could benefit from cognitive training despite being at-risk carriers for a given gene. Moreover, our APOE $\varepsilon 4$ carrier group might be considered as a prodomic AD sample, although they did not suffer memory or global cognitive loss at the time of evaluation. Another possible limitation of the study is related to the fact that we only studied the impact of a single, isolated gene. There is currently increasing focus on the interaction among genes. In this sense, it has been shown that multiple genetic influences and cognitive outcomes may more accurately predict cognitive performance-or impairment-than the effect of a single, isolated gene. For example, besides the APOE gene, the catechol-O-methyl transferase $(C O M T)$ or the brain-derived neurotrophic factor $(B D N F)$ have been linked to cognitive decline or to abilities that could contribute to this synergistic effect [76-81]. In addition, not just the interaction among genes should be considered, but also their possible antagonistic pleiotropic effect throughout the lifespan [37-40]. All of this raises environmental influence as a modulation of gene expression and the need to carry out longitudinal studies in order to better understand the genetic implications in cognitive abilities in old age, as well as across the entire lifecycle. 
In addition, as we have pointed out in the discussion section, the UMAM program includes activities related to reading comprehension. So, in this sense, benefits of training in the language domain could be considered near transfer effects. Nevertheless, the absence of training benefits on memory or executive functions should be controversial. That is why future studies also have to explore in which conditions those domains might be strong and positively influenced by cognitive training.

On the other hand, our results could have a tentative explanation if one considers that $A P O E \varepsilon 4$ carriers have a specific cognitive profile characterized by a greater neural activation (as happens in older adults with subjective cognitive decline; see for example [82]), in order to compensate their incipient cognitive problems. As mentioned in the introduction, this greater neural activation could be due to the negative effects that the $A P O E \varepsilon 4$ carriage seems to produce in the brain (e.g., increased glial activation, oxidative stress, or neuronal injury [21]), which could result in altered brain repair mechanisms and in a less effective neural protection. Thus, those carriers of the $A P O E \& 4$ allele could possibly need to recruit additional neural networks or resources to give response to task demands involved in their daily lives. This would be made for the purpose of balancing this hypothetical brain disruption, although sometimes this over-activation of the brain circuitry could still remain ineffective $[83,84]$. In other words, we hypothesize that despite the greater neural activation that the APOE $\varepsilon 4$ allele carriers could suffer to cope with task demands, they are not able to benefit themselves from cognitive training. Regarding the $A P O E \& 4$ noncarriers, an extra recruitment of additional or alternative neural networks would not be necessarily required since it is assumed that they would not present "the same brain damages" as the ones attributed to the carrier group. On the contrary, they have obtained positive results from the cognitive training intervention which could be also presumable to produce neural network reorganizations or even new connections. However, we are not able to elucidate why despite training several cognitive domains (e.g., memory, executive functioning, etc.), the $A P O E$ genotype modulation has been mainly restricted to the sentence comprehension area. In any case, we should bear in mind that this is only a speculative explanation on how the APOE $\varepsilon 4$ allele could modulate the intervention effects and this might be another line of future research which could also be supported by neuroimaging tests.
In summary, future studies should promote the inclusion of all of these aspects, which may contribute to the improvement of our comprehension on how genetic mechanisms interact with cognitive processes. All of this has the ultimate goal of determining how to use this knowledge to conduct for example, more appropriate cognitive neurorehabilitation therapies.

\section{ACKNOWLEDGMENTS}

This study was supported by a predoctoral fellowship from the Spanish Ministry of Education, Culture and Sports (FPU13/02064) to ICRR, and by the Spanish Ministry of Economy and Competitiveness under Grant PSI2012-38375-C03-03.

Authors' disclosures available online (http://j-alz. com/manuscript-disclosures/16-1014r3).

\section{SUPPLEMENTARY MATERIAL}

The supplementary material is available in the electronic version of this article: http://dx.doi.org/ 10.3233/JAD-161014.

\section{REFERENCES}

[1] Giuli C, Fattoretti P, Gagliardi C, Mocchegiani E, Venarucci D, Balietti M, Casoli T, Costarelli L, Giacconi R, Malavolta M, Papa R, Lattanzio F, Postacchini D (2016) My Mind Project: The effects of cognitive training for elderlythe study protocol of a prospective randomized intervention study. Aging Clin Exp Res. doi: 10.1007/s40520-0160570-1

[2] Giuli C, Papa R, Lattanzio F, Postacchini D (2016) The effects of cognitive training for elderly: Results from My Mind Project. Rejuvenation Res 19, 485-494.

[3] Martin M, Clare L, Altgassen AM, Cameron MH, Zehnder F (2011) Cognition-based interventions for healthy older people and people with mild cognitive impairment. Cochrane Database Syst Rev 19, CD006220.

[4] Pappa K, Walsh S, Snyder P (2009) Immediate and delayed effects of cognitive interventions in healthy elderly: A review of current literature and future directions. Alzheimers Dement 5, 50-60.

[5] Ball K, Berch DB, Helmers KF, Jobe JB, Leveck MD, Marsiske M, Morris JN, Rebok GW, Smith DM, Tennstedt SL, Unverzagt FW, Willis SL, Advanced Cognitive Training for Independent and Vital Elderly Study Group (2002) Effects of cognitive training interventions with older adults: A randomized controlled trial. JAMA 288, 2271-2281.

[6] Willis SL, Caskie GIL (2013) Reasoning training in the ACTIVE study: How much is needed and who benefits? $J$ Aging Health 25, 43S-64S.

[7] Edwardas JD, Xu H, Clark D, Ross LA, Unverzagt FW (2016) The ACTIVE study: What we have learned and what is next? Cognitive training reduces incident dementia across ten years. Alzheimers Dement 12, 212. 
[8] Ngandu T, Lehtisalo J, Solomon A, Levälahti E, Ahtiluoto S, Antikainen R, Bäckman L, Hänninen T, Jula A, Laatikainen T, Lindström J, Mangialasche F, Paajanen T, Pajala S, Peltonen M, Rauramaa R, Stigsdotter-Neely A, Strandberg T, Tuomilehto J, Soininen H, Kivipelto M (2015) A 2-year multidomain intervention of diet, exercise, cognitive training, and vascular risk monitoring versus control to prevent cognitive decline in at-risk elderly people (FINGER): A randomised controlled trial. Lancet 385, 2255-2263.

[9] Lampit A, Hallock H, Valenzuela M (2014) Computerized cognitive training in cognitively healthy older adults: A systematic review and meta-analysis of effect modifiers. PLoS Med 11, e1001756.

[10] Jagust W (2009) Genes and cognitive aging. Front Neurosci 3, 161-163.

[11] Chartier-Harlin MC, Parfitt M, Legrain S, Pérez-Tur J, Brousseau T, Evans A, Berr C, Vidal O, Roques P, Gourlet V (1994) Apolipoprotein E, epsilon 4 allele as a major risk factor for sporadic early and late-onset forms of Alzheimer's disease: Analysis of the 19q13.2 chromosomal region. Hum Mol Genet 3, 569-574.

[12] Corder EH, Saunders AM, Strittmatter WJ, Schmechel DE, Gaskell PC, Small GW, Roses AD, Haines JL, PericakVance MA (1993) Gene dose of apolipoprotein E type 4 allele and the risk of Alzheimer's disease in late onset families. Science 261, 921-923.

[13] Houlden H, Crook R, Backhovens H, Prihar G, Baker M, Hutton M, Rossor M, Martin JJ, Van Broeckhoven C, Hardy J (1998) ApoE genotype is a risk factor in nonpresenilin early-onset Alzheimer's disease families. Am J Med Genet 81, 117-121.

[14] Paulson HL, Igo I (2011) Genetics of dementia. Semin Neurol 31, 449-460.

[15] Hanlon CS, Rubinsztein DC (1995) Arginine residues at codons 112 and 158 in the apolipoprotein E gene correspond to the ancestral state in humans. Atherosclerosis 112, 85-90.

[16] Mahley RW (1988) Apolipoprotein E: Cholesterol transport protein with expanding role in cell biology. Science $\mathbf{2 4 0 ,}$ 622-630.

[17] Mahley RW, Rall SC (2000) Apolipoprotein E: Far more than a lipid transport protein. Annu Rev Genomics Hum Genet 1, 507-537.

[18] Liu C, Kanekiyo T, Xu H, Bu G (2013) Apolipoprotein E and Alzheimer disease: Risk, mechanisms and therapy. Nat Rev Neurol 9, 106-118.

[19] $\mathrm{Bu} \mathrm{G}$ (2009) Apolipoprotein E and its receptors in Alzheimer's disease: Pathways, pathogenesis and therapy. Nat Rev Neurosci 10, 333-344.

[20] Kim J, Basak JM, Holtzman DM (2009) The role of Apolipoprotein E in Alzheimer's disease. Neuron 63, 287303.

[21] Laskowitz DT, Vitek MP (2007) Apolipoprotein E and neurological disease: Therapeutic potential and pharmacogenomic interactions. Pharmacogenomics 8, 959-969.

[22] Ariza M, Pueyo R, Matarín M, del M, Junqué C, Mataró M, Clemente I, Moral P, Poca MA, Garnacho A, Sahuquillo J (2006) Influence of APOE polymorphism on cognitive and behavioural outcome in moderate and severe traumatic brain injury. J Neurol Neurosurg Psychiatry 77, 1191-1193.

[23] Suri S, Heise V, Trachtenberg AJ, Mackay CE (2013) The forgotten APOE allele: A review of the evidence and suggested mechanisms for the protective effect of APOE $\varepsilon 2$. Neurosci Biobehav Rev 37, 2878-2886.

[24] Caselli RJ, Dueck AC, Osborne D, Sabbagh MN, Connor DJ, Ahern GL, Baxter LC, Rapcsak SZ, Shi J,
Woodruff BK, Locke DEC, Snyder CH, Alexander GE, Rademakers R, Reiman EM (2009) Longitudinal modeling of age-related memory decline and the APOE $\varepsilon 4$ effect. $N$ Engl J Med 361, 255-263.

[25] Filippini N, Ebmeier KP, MacIntosh BJ, Trachtenberg AJ, Frisoni GB, Wilcock GK, Beckmann CF, Smith SM, Matthews PM, Mackay CE (2011) Differential effects of the APOE genotype on brain function across the lifespan. Neuroimage 54, 602-610.

[26] Izaks GJ, Gansevoort RT, Van der Knaap AM, Navis G, Dullaart RPF, Slaets JPJ (2011) The association of APOE genotype with cognitive function in persons aged 35 years or older. PLoS One 6, e27415.

[27] Bretsky P, Guralnik JM, Launer L, Albert M, Seeman TE, MacArthur Studies of Successful Aging (2003) The role of APOE-epsilon4 in longitudinal cognitive decline: MacArthur Studies of Successful Aging. Neurology 60, 1077-1081.

[28] Bondi MW, Salmon DP, Monsch AU, Galasko D, Butters N, Klauber MR, Thal LJ, Saitoh T (1995) Episodic memory changes are associated with the APOE-epsilon 4 allele in nondemented older adults. Neurology 45, 2203-2206.

[29] Honea RA, Vidoni E, Harsha A, Burns JM (2009) Impact of APOE on the healthy aging brain: A voxel-based MRI and DTI study. J Alzheimers Dis 18, 553-564.

[30] Praetorius M, Thorvaldsson V, Hassing LB, Johansson B (2013) Substantial effects of apolipoprotein E $\varepsilon 4$ on memory decline in very old age: Longitudinal findings from a population-based sample. Neurobiol Aging 34, 2734-2739.

[31] Wilson RS, Schneider JA, Barnes LL, Beckett LA, Aggarwal NT, Cochran EJ, Berry-Kravis E, Bach J, Fox JH, Evans DA, Bennett DA (2002) The apolipoprotein E epsilon 4 allele and decline in different cognitive systems during a 6-year period. Arch Neurol 59, 1154-1160.

[32] Feng W, Yokoyama JS, Yu S, Chen Y, Cheng Y, Bonham LW, Wang D, Shen Y, Wu W, Li C (2015) APOE genotype affects cognitive training response in healthy Shanghai communitydwelling elderly individuals. J Alzheimers Dis 47, 10351046.

[33] Luck T, Then FS, Luppa M, Schroeter ML, Arélin K, Burkhardt R, Thiery J, Löffler M, Villringer A, RiedelHeller SG (2014) Association of the apolipoprotein E genotype with memory performance and executive functioning in cognitively intact elderly. Neuropsychology 29, 382-387.

[34] Wisdom NM, Callahan JL, Hawkins KA (2011) The effects of apolipoprotein $\mathrm{E}$ on non-impaired cognitive functioning: A meta-analysis. Neurobiol Aging 32, 63-74.

[35] Small BJ, Rosnick CB, Fratiglioni L, Bäckman L (2004) Apolipoprotein $\mathrm{E}$ and cognitive performance: A metaanalysis. Psychol Aging 19, 592-600.

[36] Smits LL, Pijnenburg YAL, Van der Vlies AE, Koedam ELGE, Bouwman FH, Reuling IEW, Scheltens P, Van der Flier WM (2015) Early onset APOE E4-negative Alzheimer's disease patients show faster cognitive decline on non-memory domains. Eur Neuropsychopharmacol 25, $1-8$.

[37] Jochemsen HM, Muller M, Van der Graaf Y, Geerlings MI (2012) APOE $\varepsilon 4$ differentially influences change in memory performance depending on age. The SMART-MR study. Neurobiol Aging 33, 832.e15-22.

[38] Mondadori CRA, de Quervain DJ-F, Buchmann A, Mustovic $\mathrm{H}$, Wollmer MA, Schmidt CF, Boesiger P, Hock C, Nitsch RM, Papassotiropoulos A, Henke K (2007) Better 
memory and neural efficiency in young apolipoprotein $\mathrm{E}$ epsilon4 carriers. Cereb Cortex 17, 1934-1947.

[39] Haan MN, Mayeda ER (2010) Apolipoprotein E genotype and cardiovascular diseases in the elderly. Curr Cardiovasc Risk Rep 4, 361-368.

[40] Nilsson LG, Adolfsson R, Bäckman L, Cruts M, Nyberg L, Small BJ, Van Broeckoven C (2006) The influence of APOE status on episodic and semantic memory: Data from a population-based study. Neuropsychology 20, 645-657.

[41] Stening E, Persson J, Eriksson E, Wahlund L, Zetterberg $\mathrm{H}$, Söderlund H (2016) Apolipoprotein E $\varepsilon 4$ is positively related to spatial performance but unrelated to hippocampal volume in healthy young adults. Behav Brain Res 299, 11-18.

[42] Bunce D, Anstey KJ, Burns R, Christensen H, Easteal S (2011) Does possession of apolipoprotein $\mathrm{E} \varepsilon 4$ benefit cognitive function in healthy young adults? Neuropsychologia 49, 1693-1697.

[43] Filippini N, MacIntosh BJ, Hough MG, Goodwin GM, Frisoni GB, Smith SM, Matthews PM, Beckmann CF, Mackay CE (2009) Distinct patterns of brain activity in young carriers of the APOE-epsilon4 allele. Proc Natl Acad Sci U S A 106, 7209-7214.

[44] Polito L, Abbondanza S, Vaccaro R, Valle E, Davin A, Degrate A, Villani S, Guaita A (2015) Cognitive stimulation in cognitively impaired individuals and cognitively healthy individuals with a family history of dementia: Short-term results from the "Allena-Mente" randomized controlled trial. Int J Geriatr Psychiatry 30, 631-638.

[45] Zehnder AE, Bläsi S, Berres M, Monsch AU, Stähelin HB, Spiegel R (2009) Impact of APOE status on cognitive maintenance in healthy elderly persons. Int J Geriatr Psychiatry 24, 132-141.

[46] Folstein MF, Folstein SE, McHugh PR (1975) “Mini-mental state": A practical method for grading the cognitive state of patients for the clinician. J Psychiatr Res 12, 189-198.

[47] Lobo A, Saz P, Marcos G, GT ZARADEMP (2002) MMSE examen cognoscitivo mini-mental [MMSE mini-mental cognitive test], TEA, Madrid.

[48] Sheikh JL, Yesavage JA (1986) Geriatric Depression Scale (GDS): Recent evidence and development of a shorter version. Clin Gerontol 5, 165-173.

[49] Fischl B, Salat DH, Busa E, Albert M, Dieterich M, Haselgrove C, van der Kouwe A, Killiany R, Kennedy D, Klaveness S, Montillo A, Makris N, Rosen B, Dale AM (2002) Whole brain segmentation: Automated labeling of neuroanatomical structures in the human brain. Neuron 33, 341-355.

[50] Montejo P, Montenegro M, Reinoso AI, De Andrés ME, Claver MD (2013) El método UMAM de entrenamiento de Memoria [The UMAM Memory training method], Centro de Prevención del Deterioro Cognitivo, Madrid Salud, Ayuntamiento de Madrid.

[51] Wechsler D (2004) WMS-III. Escala de memoria de Wechsler-III: Manual de aplicación y puntuación [Wechsler Memory Scale-III: Application and scoring manual], TEA (Orig. 1997), Madrid.

[52] Golden CJ (1978) The Stroop Color and Word Test: A manual for clinical and experimental uses, Stoelting, Chicago.

[53] López-Higes R, Rubio S, Martín-Aragoneses MT, Del Río D, Mejuto G (2012) Evaluación de la comprensión gramatical en el envejecimiento normal y patológico: Un resumen de los resultados obtenidos con las baterías ECCO y ECCOSenior [Assessment of grammar comprehension in normal and pathological aging: An overview of the results obtained with ECCO and ECCO-Senior batteries]. Int J Psychol Res 5, 96-108.

[54] Rami L, Valls-Pedret C, Bartrés-Faz D, Caprile C, SoléPadullés C, Castellvi M, Olives J, Bosch B, Molinuevo JL (2011) Cuestionario de Reserva Cognitiva. Valores obtenidos en población anciana sana y con enfermedad de Alzheimer [Cognitive Reserve Questionnaire. Scores obtained in a healthy elderly population and in one with Alzheimer's disease]. Rev Neurol 52, 195-201.

[55] Chafetz M, Matthews L (2004) A new interference score for the Stroop test. Arch Clin Neuropsychol 19, 555-567.

[56] Gueorguieva R, Krystal JH (2004) Move over ANOVA: Progress in analyzing repeated-measures data and its reflection in papers published in the Archives of General Psychiatry. Arch Gen Psychiatry 61, 310-317.

[57] Gámiz F, Gallo M (2011) Taste learning and memory: A window on the study of brain aging. Front System Neurosci 5, 91-97.

[58] Tardif S, Simard M (2011) Cognitive stimulation programs in healthy elderly: A review. Int J Alzheimers Dis 2011, $1-13$.

[59] Novoa AM, Juárez O, Nebot M (2008) Review of the effectiveness of cognitive interventions in preventing cognitive deterioration in healthy elderly individuals. Gac Sanit 22, 474-482.

[60] Kelly ME, Loughrey D, Lawlor BA, Robertson IH, Walsh C, Brennan S (2014) The impact of cognitive training and mental stimulation on cognitive and everyday functioning of healthy older adults: A systematic review and meta-analysis. Ageing Res Rev 15, 28-43.

[61] Shipstead Z, Redick TS, Engle RW (2010) Does working memory training generalize? Psychol Belg 50, 245-276.

[62] de Jonge P, de Jong PF (1996) Working memory, intelligence and reading ability in children. Pers Individ Dif 21, 10071020.

[63] Buschkuehl M, Jaeggi SM (2010) Improving intelligence: A literature review. Swiss Med Wkly 140, 266-272.

[64] Jaušovec N, Jaušovec K (2012) Working memory training: Improving intelligence - Changing brain activity. Brain Cogn 79, 96-106.

[65] Morrison AB, Chein JM (2011) Does working memory training work? The promise and challenges of enhancing cognition by training working memory. Psychon Bull Rev 18, 46-60.

[66] Jaeggi SM, Buschkuehl M, Jonides J, Perrig WJ (2008) Improving fluid intelligence with training on working memory. Proc Natl Acad Sci U S A 105, 6829-6833.

[67] Redick TS, Shipstead Z, Harrison TL, Hicks KL, Fried DE, Hambrick DZ, Kane MJ, Engle RW (2013) No evidence of intelligence improvement after working memory training: A randomized, placebo-controlled study. J Exp Psychol Gen 142, 359-579.

[68] Salminen T, Strobach T, Schubert T (2012) On the impacts of working memory training on executive functioning. Front Hum Neurosci 6, 166.

[69] Robinson FP (1970) Effective Study, Ed. Harper \& Row, New York.

[70] Montejo P, Montenegro M (2006) Memoria cotidiana en los mayores [Everyday memory in the elderly]. Madrid, Portal Mayores, Informes Portal Mayores, $\mathrm{n}^{\circ}$ 60. Lecciones de Gerontología, VIII, http://www.imsersomayores.csic. es/documentos/documentos/montejo-memoria-01.pdf, Posted 19 September 2006, Accessed Ma 25, 2016.

[71] Hill NT, Mowszowski L, Naismith SL, Chadwick VL, Valenzuela M, Lampit A (2016) Computerized cognitive 
training in older adults with mild cognitive impairment or dementia: A systematic review and meta-Analysis. Am J Psychiatry 14, 1-12.

[72] Mayeux R, Small SA, Tang M, Tycko B, Stern Y (2001) Memory performance in healthy elderly without Alzheimer's disease: Effects of time and apolipoprotein-E. Neurobiol Aging 22, 683-689.

[73] Gispert JD, Rami L, Sánchez-Benavides G, Falcon C, Tucholka A, Rojas S, Molinuevo JL (2015) Nonlinear cerebral atrophy patterns across the Alzheimer's disease continuum: Impact of APOE4 genotype. Neurobiol Aging 36, 2687-2701.

[74] Pievani M, Galluzzi S, Thompson PM, Rasser PE, Bonetti M, Frisoni GB (2011) APOE4 is associated with greater atrophy of the hippocampal formation in Alzheimer's disease. Neuroimage 55, 909-919.

[75] Tang X, Holland D, Dale AM, Miller MI, Alzheimer's Disease Neuroimaging Initiative (2015) APOE affects the volume and shape of the amygdala and the hippocampus in mild cognitive impairment and Alzheimer's disease: Age matters. J Alzheimers Dis 47, 645-660.

[76] Das D, Tan X, Bielak AAM, Cherbuin N, Easteal S, Anstey KJ (2014) Cognitive ability, intraindividual variability, and common genetic variants of catechol-O-methyltransferase and brain-derived neurotrophic factor: A longitudinal study in a population-based sample of older adults. Psychol Aging 29, 393-403.

[77] Laukka EJ, Lövdén M, Herlitz A, Karlsson S, Ferencz B, Pantzar A, Keller L, Graff C, Fratiglioni L, Bäckman L (2013) Genetic effects on old-age cognitive functioning: A population-based study. Psychol Aging 28, 262-274.
[78] Lanni C, Garbin G, Lisa A, Biundo F, Ranzenigo A, Sinforiani E, Cuzzoni G, Govoni S, Ranzani GN, Racchi M (2012) Influence of COMT Val158Met polymorphism on Alzheimer's disease and mild cognitive impairment in Italian patients. J Alzheimers Dis 32, 919-926.

[79] Ji Y, Shi Z, Liu M, Liu S, Liu S, Wang J (2014) Association between the COMT Val158Met genotype and Alzheimer's disease in the Han Chinese population. Dement Geriatr Cogn Disord Extra 4, 14-21.

[80] Wollam ME, Weinstein AM, Saxton JA, Morrow L, Snitz B, Fowler NR, Suever Erickson BL, Roecklein KA, Erickson KI, Wollam ME, Weinstein AM, Saxton JA, Morrow L, Snitz B, Fowler NR, Suever Erickson BL, Roecklein KA, Erickson KI (2015) Genetic risk score predicts late-life cognitive impairment. J Aging Res 2015, 1-8.

[81] Raz N, Rodrigue KM, Kennedy KM, Land S (2009) Genetic and vascular modifiers of age-sensitive cognitive skills: Effects of COMT, BDNF, ApoE, and hypertension. Neuropsychology 23, 105-116.

[82] Maestú F, Baykova E, Ruiz JM, Montejo P, Montenegro M, Llanero M, Solesio E, Gil-Gregorio P, Yubero R, Paúl N, Pozo F, Nevado A (2011) Increased biomagnetic activity in healthy elderly with subjective memory complaints. Clin Neurophysiol 123, 499-505.

[83] Logan JM, Sanders AL, Snyder AZ, Morris JC, Buckner RL (2002) Under-recruitment and nonselective recruitment. Neuron 33, 827-840.

[84] Reuter-Lorenz PA, Cappell KA (2008) Neurocognitive aging and the compensation hypothesis. Curr Dir Psychol Sci 17, 177-182. 